\title{
AVALIAÇÃO METROLÓGICA DE UM ROBÔ INDUSTRIAL PARA MONTAGEM ESTRUTURAL DE AERONAVES
}

\author{
Emília Villani ${ }^{1 *}$ \\ evillanieita.br \\ Luís Gonzaga Trabasso ${ }^{1 *}$ \\ gonzagaeita.br \\ Bolivar H. L. Alvarado ${ }^{1 *}$ \\ bolivareita.br \\ Ricardo Suterio ${ }^{1,2 \dagger}$ \\ suteriodit.inpe.br \\ Luís F. F. Furtado ${ }^{1 *}$ \\ furtadodita.br \\ Daniel Y. K. Amorim ${ }^{1 *}$ \\ danielyuji@gmail.com \\ ${ }^{* 1}$ Instituto Tecnológico de Aeronáutica - ITA, \\ Praça Marechal Eduardo Gomes 50, \\ São José dos Campos, São Paulo, Brasil \\ ${ }^{\dagger}$ Instituto Nacional de Pesquisas Espaciais - INPE, \\ Av. dos Astronautas 1758, \\ São José dos Campos, São Paulo, Brasil
}

\begin{abstract}
Metrological analysis of an industrial robot for aircraft fuselage assembly

The aircraft fuselage assembly process is too labor intensive and highly manual within the Brazilian aircraft industry. Foreign companies of this industrial segment started the adoption of automated solutions in the last two decades. Their automated solutions are very product dependent as well as very expensive. This kind of solution is inadequate for the Brazilian aircraft industry. This paper shows the preliminary results of a flexible, low cost automated system specially designed to fit the Brazilian requirements. This is based upon the usage of industrial robots for general purposes. In order to check the feasibility of such a solution, the process requirements are expressed in terms of accuracy, repeatability and resolution of the robots. These characteristics are measured by two independent, state-of-art measurement systems, namely, Indoor GPS and photogrammetry device. The initial results allow one to
\end{abstract}

Artigo submetido em 21/10/2009 (Id.: 01068)

Revisado em 30/04/2010, 27/05/2010

Aceito sob recomendação do Editor Associado Prof. Marco Henrique Terra conclude that the robot can be used for the purpose described herein as long as it is assisted by correction process based upon the very measurement systems used to acquire its operational characteristics.

KEYWORDS: High volume measurement systems, indoor GPS, photogrammetry devices, aircraft fuselage assembly, robotic assembly.

\section{RESUMO}

A montagem estrutural de fuselagens de aeronaves tem sido realizada de forma manual na indústria aeronáutica brasileira desde o início de suas atividades. Outros fabricantes de aeronaves empregam equipamentos de grandes dimensões para realizar montagens de forma automatizada há várias décadas. Estas máquinas normalmente são dedicadas a um produto e requerem grandes investimentos incompatíveis com a realidade brasileira. Este trabalho apresenta os primeiros resultados de uma iniciativa nacional para projetar, desenvolver e testar um sistema flexível e de baixo custo de automação da montagem estrutural de aeronaves, adequado à realidade brasileira, baseada no uso de robôs industriais. 
Para avaliar a factibilidade do uso de robôs na montagem de fuselagens, são definidos os requisitos do processo traduzidos pela exatidão, repetitividade e resolução do robô. Estas grandezas são medidas por dois sistemas metrológicos de grandes volumes inéditos no Brasil. A análise dos resultados obtidos permite concluir que o uso de robôs no processo de junção de fuselagens somente é viável com a integração de sistemas auxiliares de correção de posição e atitude.

KEYWORDS: Sistema de medição de grandes volumes, GPS indoor, dispositivos de fotogrametria, montagem de fuselagem aeronáutica, montagem robotizada.

\section{INTRODUÇÃO}

A evolução da indústria aeronáutica nas últimas décadas foi caracterizada por uma drástica redução do número de empresas fornecedoras. Em 1980, os Estados Unidos contavam com mais de 70 empresas fornecedoras, número este que foi reduzido para apenas 5 empresas principais em 2004. As empresas que permaneceram no mercado organizaram sua cadeia de suprimento em redes do tipo 3-tiers, de forma semelhante à indústria automobilística, onde a empresa fornecedora de aeronaves ocupa o primeiro tier e é responsável pela prospecção de mercado, projeto de aeronave e montagem do produto final (Cibiel e Prat, 2006).

Para manter a competitividade neste cenário, um dos principais desafios das empresas fornecedoras de aeronaves é a automação dos processos de montagem estrutural. A automação é essencial na redução de custo, de tempo ciclo de processo, e para aprimoramento da qualidade do produto final (Iovenitti et al, 2001; Kleebaur, 2005). Há várias formas para a implantação da automação no setor aeronáutico, dentre elas, aquela que utiliza robôs industriais de uso geral e/ou customizados para um processo específico. Há vários benefícios associados à utilização de robôs. Para o processo de rebitagem, por exemplo, destaca-se a eliminação do uso de gabaritos dedicados para furação. Estes gabaritos são necessários quando a operação é realizada de forma manual e tem um custo elevado para o fornecedor. Para a indústria aeronáutica brasileira, em particular, a automação é um recurso essencial para sua sobrevivência num mercado globalizado.

Neste contexto, este artigo aborda a automação do processo de montagem estrutural de aeronaves utilizando robôs. A solução para automação do processo de montagem estrutural de aeronaves varia de acordo com a etapa do processo. A Figura 1 ilustra algumas das diversas etapas da montagem estrutural de uma aeronave, desde a composição de painéis, até a obtenção dos painéis de fuselagem e de sua junção final.

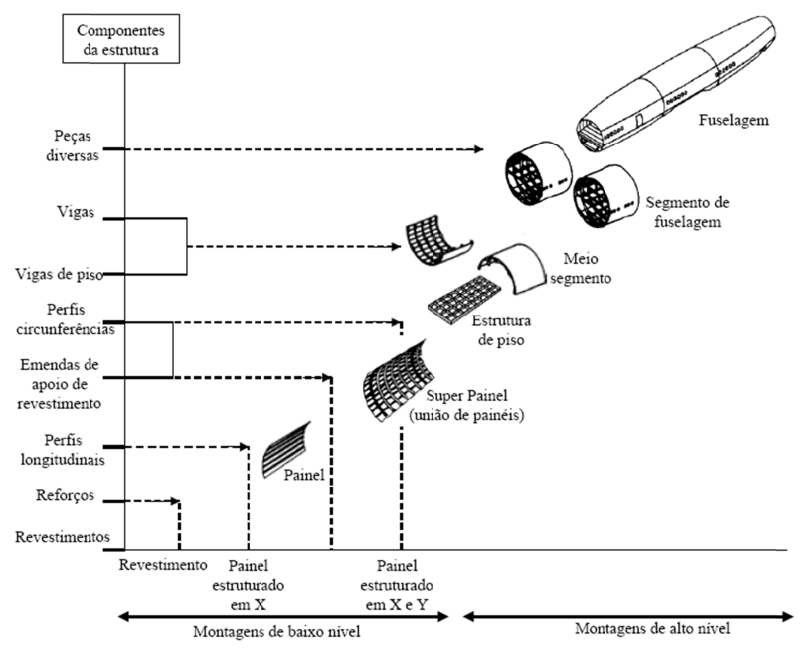

Figura 1: Etapas da montagem estrutural de aeronaves (Munroe et al, 2000).

A montagem estrutural de baixo nível é caracterizada por um grande número de operações de rebitagem, que justifica o desenvolvimento de máquinas dedicadas para sua automação, também chamadas de máquinas monumentais. No entanto, o mesmo não se aplica às montagens de alto nível, onde o número de operações é menor e as restrições de acesso e nivelamento das partes exigem soluções de maior flexibilidade. Seguindo o conceito de sistemas flexíveis de manufatura, a indústria aeronáutica tem caminhado na direção da utilização de robôs industriais para a automação destas etapas do processo de montagem estrutural de aeronaves.

A Figura 2 ilustra qualitativamente o tipo de solução mais adequado, considerando o número de operações de inserção de prendedor realizado por ano e o tipo de junção.

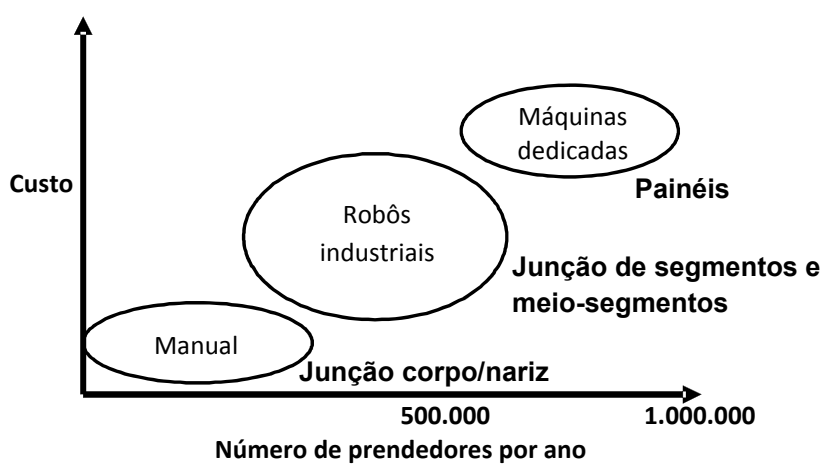

Figura 2: Automação da montagem estrutural de aeronaves.

Para cada aeronave, a montagem dos painéis exige um grande 
número de operações, o que justifica a aquisição de máquinas monumentais específicas para esta finalidade, de alto custo e baixa capacidade de reconfiguração. Robôs industriais têm seu campo de aplicação na junção de segmentos e meios segmentos, que são operações realizadas em menor número por aeronave. Quando comparada ao uso de máquinas monumentais, a solução robótica se justifica por sua maior flexibilidade e menor custo. De acordo com Kihlman (2005), o custo de uma máquina monumental pode chegar a 200 vezes o custo de um robô. No caso da junção corpo/nariz, a dificuldade de acesso e o número reduzido de prendedores tornam a solução manual a mais economicamente adequada.

O objetivo deste trabalho é apresentar a validação de um robô industrial para montagem estrutural de junções circulares de fuselagem utilizando dois sistemas metrológicos distintos, o GPS Indoor (iGPS) e o K-SERIES. Os resultados obtidos permitem ainda a comparação dos dois sistemas metrológicos.

O presente trabalho é parte do Projeto AME (Automação da Montagem Estrutural de Aeronaves), desenvolvido em parceria com a indústria aeronáutica brasileira e financiado pela FINEP. Este é um projeto pioneiro no Brasil no que se refere à utilização de robôs para montagem estrutural de aeronaves. Outro aspecto inovador do Projeto AME no contexto nacional é a introdução de novos sistemas para medição de grandes volumes. Atualmente, o principal sistema de medição de grandes volumes utilizado na indústria aeronáutica brasileira é o laser tracker, que realiza a medição de grandes volumes por meio da reflexão de um feixe de laser. Este trabalho analisa dois novos sistemas, o iGPS e o K-SERIES, como recursos para o processo de rebitagem automática. Comparativamente com o laser tracker, estes sistemas têm maior flexibilidade e menor exatidão, porém adequada às necessidades da aplicação.

A organização deste artigo é apresentada a seguir. A Seção 2 apresenta a revisão bibliográfica de trabalhos relacionados disponíveis na literatura. Os sistemas metrológicos utilizados neste trabalho são descritos na Seção 3. A Seção 4 apresenta a descrição do processo de junção de fuselagens, discute os conceitos de exatidão, repetitividade e resolução, quando aplicados à robótica, e identifica os requisitos do processo a serem validados. O procedimento experimental adotado para validação e discussão dos resultados obtidos é apresentado na Seção 5. A Seção 6 apresenta as conclusões e descreve os trabalhos futuros.

\section{TRABALHOS RELACIONADOS}

Historicamente, a utilização de robôs na indústria aeronáutica enfrenta alguns desafios que têm sido objeto de diversas pesquisas por parte da comunidade científica e dos fabricantes de aeronaves. Entre estes desafios destacam-se a exatidão necessária no posicionamento do robô (da ordem de $0,5 \mathrm{~mm}$ ), a necessidade de resistência às altas cargas (da ordem de $1000 \mathrm{~N}$ ) aplicadas no contato superfície - efetuador robótico (clamp) e a tolerância de perpendicularidade necessária entre o efetuador robótico e a superfície da fuselagem (da ordem de $\pm 0,5^{\circ}$ ) (Kihlman, 2005; Cibiel e Prat, 2006; DeVlieg et al, 2002).

Uma das primeiras iniciativas nesta área é o projeto ARMA (Adaptive Robotized Multifunction Assembly), desenvolvido pela CTRI - Robotics Division da Dassault Aviation (Costa, 1996). Este projeto contemplou a integração de células para montagem experimental de painéis das aeronaves Rafale e Falcon. Foram identificados os principais desafios da utilização de robôs industriais, relacionados à dificuldade de atingir a exatidão necessária devido a fontes de erro, tais como diferenças entre dimensões reais das peças e dimensões de projeto, inexatidão de posicionamento dos robôs, entre outras.

Cibiel e Prat (2006) descrevem os experimentos realizados para montagem de painéis da asa da aeronave Airbus A320 utilizando um robô industrial serial KUKA, com correção de posicionamento baseada em laser tracker. DeVieg et al (2002) apresentam o desenvolvimento de um sistema utilizando o robô KUKA KR350 para furação e aplicação de rebites nos flaps do bordo de fuga da asa da aeronave Boeing F/A-18E/F Super Hornet. Neste caso, a correção de posição é realizada por uma câmera digital. Webb et al. (2006) e Webb e Jayweera (2007) apresentam os testes em laboratório de uma célula de manufatura utilizando três robôs industriais para inserção de prendedores com contraponto em painéis de uma aeronave. Neste caso, o sistema metrológico utiliza sensores a laser.

Kihlman et al. (2003) apresentam os resultados obtidos no projeto europeu ADFAST, que tem como objetivo a integração de sistemas metrológicos a robôs industriais para aplicações de baixo volume de produção, alta exatidão e com necessidade de compensação de forças dinâmicas. O sistema metrológico utilizado neste caso é baseado em interferometria a laser e supervisiona a ferramenta acoplada ao robô.

Freemann (2006) propõe a compensação de erros de posicionamento por software e em tempo real para mecanismos com 5 graus de liberdade. A proposta utiliza o sistema lasertracker para identificação dos erros de posicionamento no espaço de trabalho.

Summers (2005) apresenta os trabalhos desenvolvidos na Airbus para definir a exatidão de robôs industriais com envelope de trabalho completo e restrito, com cargas dinâmicas e estáticas. Também descreve uma proposta 
de controle adaptativo para corrigir posicionamento em sistemas com múltiplos robôs.

Em relação aos trabalhos mencionados, o sistema proposto mantém o uso de robôs industriais de uso genérico, tal como em Cibiel e Prat (2006) e DeVieg et al (2002), mas substitui os sistemas metrológicos baseados em câmeras (DeVieg et al, 2002) e no sistema lasertracker (Cibiel e Prat 2006) pela tecnologia de fotogrametria e avalia também como opção de integração metrológica, o sistema iGPS, considerado o estado-da-arte desta área.

\section{SISTEMAS METROLÓGICOS}

Dois sistemas metrológicos são utilizados para medição de grandes volumes e verificação da exatidão do robô analisada neste trabalho. São eles, K-SERIES e iGPS, detalhados a seguir.

\subsection{K-SERIES}

O sistema de medição K-SERIES (Metris, 2005; Melo et al, 2008), apresentado na Figura 3a, é um sistema de medição por fotogrametria composto por três câmeras que operam no espectro infravermelho. As câmeras determinam a posição espacial de LEDs instalados no mensurando ou pela movimentação de um apalpador também equipado com os LEDs que, ao tocar pontos de uma superfície, registra a posição destes pontos no espaço (Figura 3b). Tanto para os LEDs quanto para o apalpador, cada câmera filtra o sinal vertical ou horizontal do LED e calcula a posição cartesiana do ponto. Para determinar a orientação do mensurando, além de sua posição, deve-se instalar um arranjo com três LEDs, criando, assim, um plano. A Figura 4 esquematiza o princípio de funcionamento do sistema K-SERIES.

O sistema K-SERIES apresenta uma exatidão especificada de até $60 \mu \mathrm{m}$ com uma confiabilidade de $95 \%$ e resolução de 2 $\mu \mathrm{m}$ a $2500 \mathrm{~mm}$ de distância da câmera (Metris, 2005).

\section{2 iGPS}

O sistema de medição GPS Indoor (iGPS) (Seong-Ho e Delbert, 2004; Metris, 2008; Melo et al, 2008) é um equipamento para utilização em espaços interiores baseado no conceito do sistema GPS de satélites (Global Positioning System). Ele utiliza o mesmo princípio de triangulação para a completa localização de um ponto no espaço. Entre as principais vantagens do iGPS está a liberdade de movimentação dos pontos do mensurando enquanto são realizadas as medições, sem necessidade de movimentação do sistema de medição. O iGPS é composto por transmissores que são fixos no ambiente de trabalho e
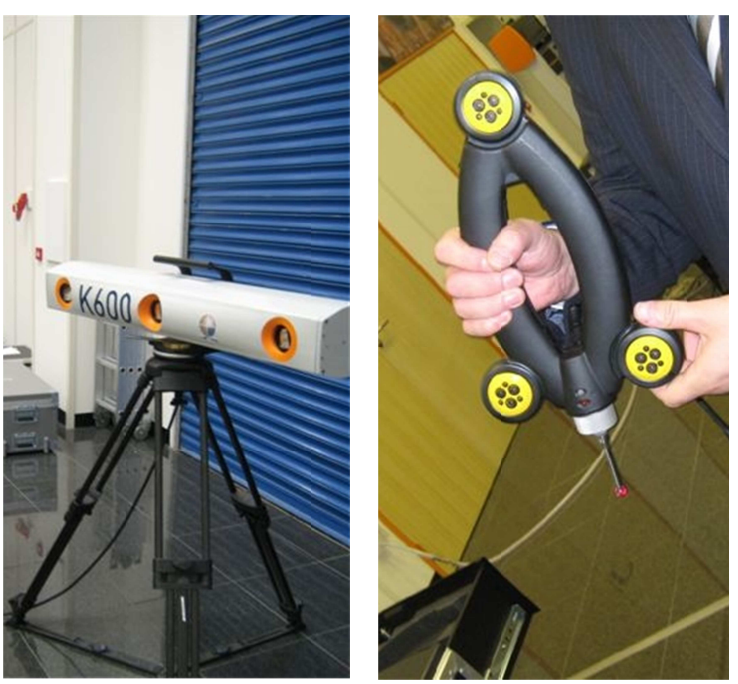

Figura 3: Sistema de medição por fotogrametria e apalpador.

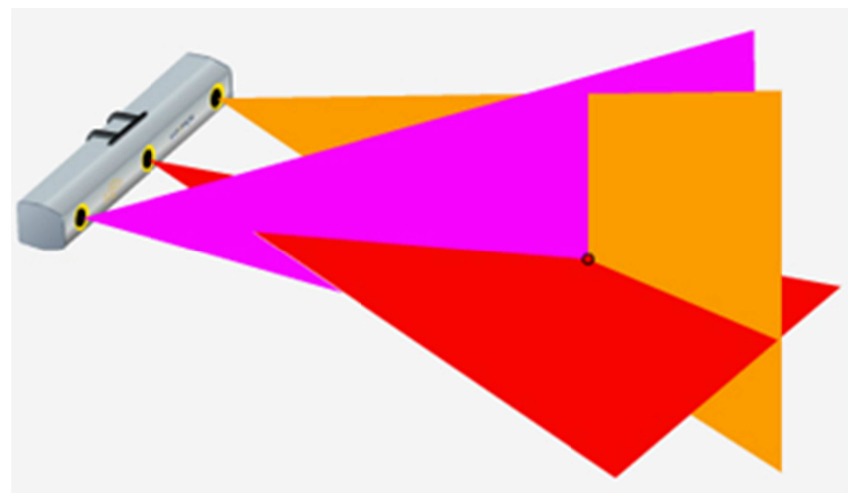

Figura 4: Esquema do princípio de funcionamento para identificação da posição de um ponto no espaço do sistema K-SERIES.

sensores que podem ser móveis e que são associados aos pontos a serem medidos (Figura 5).

A localização de um ponto no espaço é obtida por meio de transmissores que geram sinais de luz infravermelha na forma de dois feixes com aproximadamente $90^{\circ}$ de distância horizontal quando vistos por cima. Os feixes abrangem uma faixa de $60^{\circ}$ a partir do plano horizontal e estão inclinados $30^{\circ}$ em relação ao plano vertical, conforme esquematizado na Figura 6. A exatidão especificada do iGPS é de $0,050 \mathrm{~mm}$ para um alcance de medição de $55 \mathrm{~m}$. 


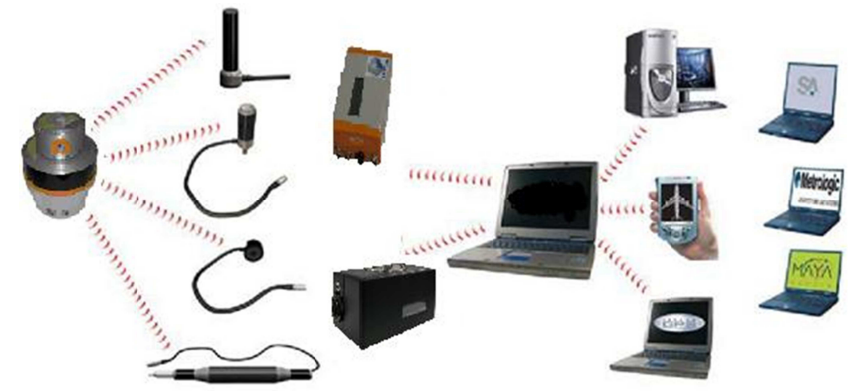

Figura 5: Visão geral do iGPS (sensores, transmissores e receptores tipo Ethernet).
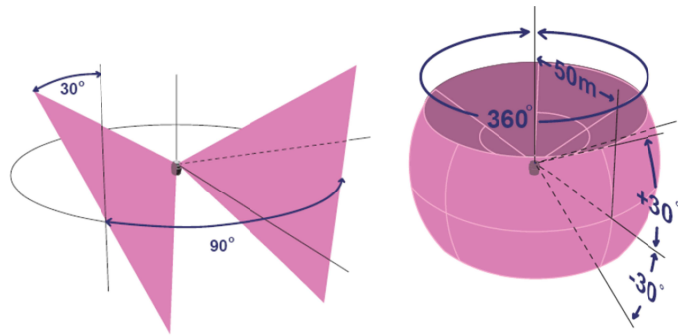

Figura 6: Disposição dos feixes e área de cobertura de um transmissor

\section{REQUISITOS DA AUTOMAÇÃO DO PROCESSO DE JUNÇÃO DE FUSELAGEM}

O processo considerado neste trabalho é o de junção de segmentos circulares de fuselagem. Este processo é composto por dois processos principais: (1) nivelamento e alinhamento dos segmentos circulares e (2) inserção de rebites na junção dos dois segmentos. $\mathrm{O}$ escopo deste trabalho refere-se à utilização de um robô industrial para o processo de inserção de prendedores. Os prendedores utilizados são rebites cegos que não requerem o uso de contraponto para instalação.

A solução adotada na automação considera que os segmentos de fuselagem têm referências previamente instaladas para auxiliar a correção de posicionamento do robô e que a posição destas referências está dentro da tolerância especificada para o processo.

O processo de inserção de rebites está organizado nas seguintes etapas:

Etapa 1) O robô se desloca até a primeira referência presente na fuselagem.
Para N referências, são realizadas as seguintes etapas:

Etapa 2) O robô corrige sua posição utilizando um sistema de visão presente no efetuador do robô. Este sistema captura uma imagem da superfície da fuselagem contendo a referência e solicita a correção da posição do robô de forma a centralizar o efetuador em relação à referência.

Para $M$ pontos de furação entre duas referências, são realizadas as seguintes etapas, de forma cíclica:

Etapa 3) O robô se desloca até o ponto de furação e inserção do rebite.

Etapa 4) O robô corrige sua orientação utilizando um sistema de medição de perpendicularidade.

Etapa 5) O efetuador realiza a furação e inserção do rebite.

Etapa 6) O robô se desloca até a próxima referência.

Três características principais referentes à calibração de robôs são determinantes na viabilidade de uma solução robótica para este processo: exatidão (também chamada de acurácia, do termo em inglês accuracy), repetitividade (também chamada de repetibilidade, do termo em inglês, repeatability) e resolução (termo em inglês resolution).

De acordo com Conrad et al. (2000), têm-se as seguintes definições para estas propriedades.

Resolução é definida como o menor movimento incremental que o robô é capaz de produzir fisicamente. Em geral, esta resolução depende principalmente do sensor de posição utilizado para fechar a malha de controle em cada eixo do robô. Eventualmente, o menor incremento possível de ser comandado é ainda limitado por software na programação do robô.

Repetitividade é a medida da habilidade do robô de retornar sempre à mesma posição e orientação quando uma mesma sequência de comandos é realizada repetidas vezes.

Exatidão é a medida da habilidade do robô de posicionar seu efetuador em um ponto desejado do volume de trabalho. Pode-se ainda distinguir entre dois tipos de exatidão: a exatidão absoluta (ou estática), referente a capacidade do robô de atingir um determinado ponto sem desvios, e a exatidão dinâmica, referente à capacidade do robô de realizar uma determinada trajetória sem desvios. Para a aplicação apresentada neste trabalho, é de interesse apenas a exatidão estática.

A exatidão, a repetitividade e a resolução determinam a viabilidade de uso do robô no processo de junção de segmentos circulares de fuselagem da seguinte forma: 
- A exatidão e repetitividade de posicionamento para distâncias da ordem de $0,5 \mathrm{~mm}$ influenciam o campo de visão necessário ao módulo de visão para determinação da posição do robô na Etapa 1 do processo.

- A resolução do robô, sua exatidão e repetitividade para deslocamentos da ordem de décimos de milímetros influenciam o erro residual de posicionamento do robô após a execução da Etapa 2.

- A exatidão e repetitividade de posicionamento para deslocamentos da ordem de poucos milímetros influenciam o número de pontos de furação que podem ser colocados entre duas referências. Isto determina o número de etapas $\mathrm{M}$ e o número de referências $\mathrm{N}$ necessárias em uma seção circular de fuselagens. Estes números dependem também do erro residual da Etapa 2.

- A exatidão e repetitividade de orientação determinam a viabilidade de utilização do robô na correção de orientação da Etapa 4. O projeto do sistema de medição de perpendicularidade não faz parte do escopo deste artigo e está detalhado em Furtado et al (2009).

\section{VALIDAÇÃO DA SOLUÇÃO ROBÓTICA}

A validação da solução robótica consistiu em determinar se o robô escolhido apresenta exatidão, repetitividade e resolução necessárias para cumprir as etapas do processo descrito na Seção 4.

Além de validar a utilização deste robô, os experimentos propostos têm como objetivo validar uma possível correção de orientação e posição automática utilizando um sistema metrológico independente, o iGPS e/ou o K-SERIES.

\subsection{Configuração do Sistema}

O robô utilizado no processo de rebitagem é o KUKA KR210 L100. A Figura 7 apresenta a área de trabalho robô-fuselagem e os sistemas de medição. A Figura 8 apresenta a configuração experimental realizada neste trabalho, indicando as orientações dos eixos de referência medidos e a instalação dos sensores iGPS e K-SERIES.

O sistema de coordenadas foi definido no centro do flange do robô para todos os procedimentos realizados com o robô e para todas as medições realizadas com os dois sistemas metrológicos.

Foi delineado um projeto de experimentos fatorial no qual o robô realiza diversas operações de deslocamento e rotação de diferentes ordens de grandeza. Foram planejadas variáveis ou fatores que contribuem no erro de posicionamento e
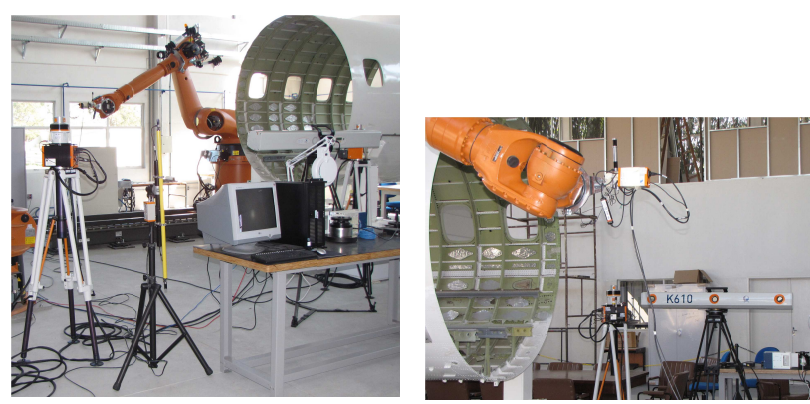

Figura 7: Área de trabalho robô-fuselagem e sistemas de medição.

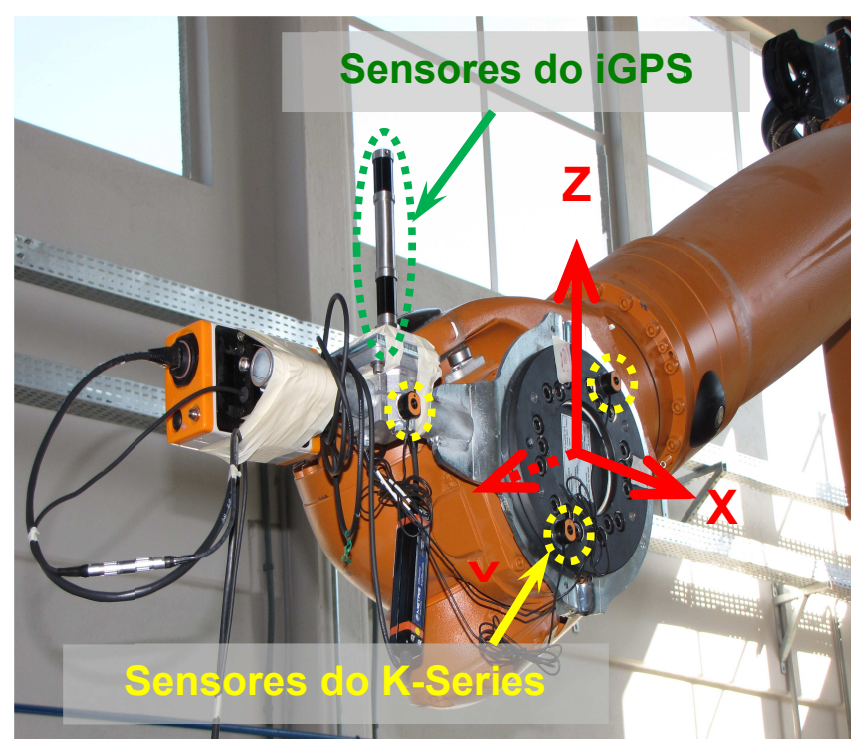

Figura 8: Configuração experimental: orientação dos eixos e instalação dos sensores de medição.

orientação como a velocidade de movimentação do robô (10\% e $100 \%$ da velocidade máxima) e a carga aplicada no flange do robô (sem carga e com carga de $100 \mathrm{~kg}$, que corresponde ao payload do robô). O projeto de experimentos está organizado em dois procedimentos de medição, descritos como se seguem. O robô inicia ambos os procedimentos em uma posição inicial, denominada $\mathrm{P} 0$, distinda da posição HOME definida pelo fabricante para o robô. O ponto $\mathrm{P} 0$ do experimento é um ponto do volume de trabalho escolhido de acordo com a conveniência para o processo de junção de fuselagem. O primeiro procedimento realizado é detalhado a seguir.

- Partindo da posição inicial P0, o robô movimenta-se para os pontos ilustrados na Figura 9 em ordem sequencial (P0, P1, P2 ... P12). Estes pontos definem um volume de trabalho a ser avaliado. Cada vez que 
Tabela 1: Projeto de Experimento Linear.

\begin{tabular}{|c|c|c|c|}
\hline \multicolumn{4}{|c|}{ Pontos Medidos } \\
\hline \multirow{2}{*}{$\begin{array}{l}\text { Deslocamento Linear do } \\
\text { Robô }\end{array}$} & \multirow{2}{*}{ Sistema de Medição } & \multicolumn{2}{|c|}{ Velocidade do Robô } \\
\hline & & $10 \%$ & $100 \%$ \\
\hline \multirow{2}{*}{$500 \mathrm{~mm}$} & K-SERIES & $(\mathrm{P} 0, \mathrm{P} 1, \mathrm{P} 2, \ldots, \mathrm{P} 12)$ & $(\mathrm{P} 0, \mathrm{P} 1, \mathrm{P} 2, \ldots, \mathrm{P} 12)$ \\
\hline & iGPS & $(\mathrm{P} 0, \mathrm{P} 1, \mathrm{P} 2, \ldots, \mathrm{P} 12)$ & $(\mathrm{P} 0, \mathrm{P} 1, \mathrm{P} 2, \ldots, \mathrm{P} 12)$ \\
\hline \multirow{2}{*}{$1 \mathrm{~mm}$} & K-SERIES & $(\mathrm{P} 0, \mathrm{P} 1, \mathrm{P} 2, \ldots, \mathrm{P} 12)$ & $(\mathrm{P} 0, \mathrm{P} 1, \mathrm{P} 2, \ldots, \mathrm{P} 12)$ \\
\hline & iGPS & $(\mathrm{P} 0, \mathrm{P} 1, \mathrm{P} 2, \ldots, \mathrm{P} 12)$ & $(\mathrm{P} 0, \mathrm{P} 1, \mathrm{P} 2, \ldots, \mathrm{P} 12)$ \\
\hline \multirow{2}{*}{$0,5 \mathrm{~mm}$} & K-SERIES & $(\mathrm{P} 0, \mathrm{P} 1, \mathrm{P} 2, \ldots, \mathrm{P} 12)$ & $(\mathrm{P} 0, \mathrm{P} 1, \mathrm{P} 2, \ldots, \mathrm{P} 12)$ \\
\hline & iGPS & $(\mathrm{P} 0, \mathrm{P} 1, \mathrm{P} 2, \ldots, \mathrm{P} 12)$ & 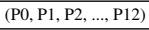 \\
\hline \multirow{2}{*}{$0,1 \mathrm{~mm}$} & K-SERIES & $(\mathrm{P} 0, \mathrm{P} 1, \mathrm{P} 2, \ldots, \mathrm{P} 12)$ & $(\mathrm{P} 0, \mathrm{P} 1, \mathrm{P} 2, \ldots, \mathrm{P} 12)$ \\
\hline & iGPS & $(\mathrm{P} 0, \mathrm{P} 1, \mathrm{P} 2, \ldots, \mathrm{P} 12)$ & $(\mathrm{P} 0, \mathrm{P} 1, \mathrm{P} 2, \ldots, \mathrm{P} 12)$ \\
\hline \multicolumn{4}{|c|}{$\begin{array}{c}\text { Pontos de medição equivalentes a P0: } \\
\text { P0, P2, P4, P6, P8, P10 e P12 } \\
\text { Sentido de medição linear em relação a P0: } \\
(-): \text { P7(x), P9(y) e P11(z). } \\
(+): \text { P1(x), P3(y) e P5(z). }\end{array}$} \\
\hline
\end{tabular}

o robô atinge um dos 13 pontos, os dois sistemas metrológicos realizam a medição de posicionamento e orientação. Os 13 movimentos foram repetidos conforme projeto experimental descrito na Tabela 1 . Foram considerados deslocamentos de $500 \mathrm{~mm}$ a $10 \%$ e $100 \%$ da velocidade máxima. Após a aquisição dos 26 pontos, o mesmo procedimento é repetido para $1 \mathrm{~mm}$, $0,5 \mathrm{~mm}$ e $0,1 \mathrm{~mm}$.

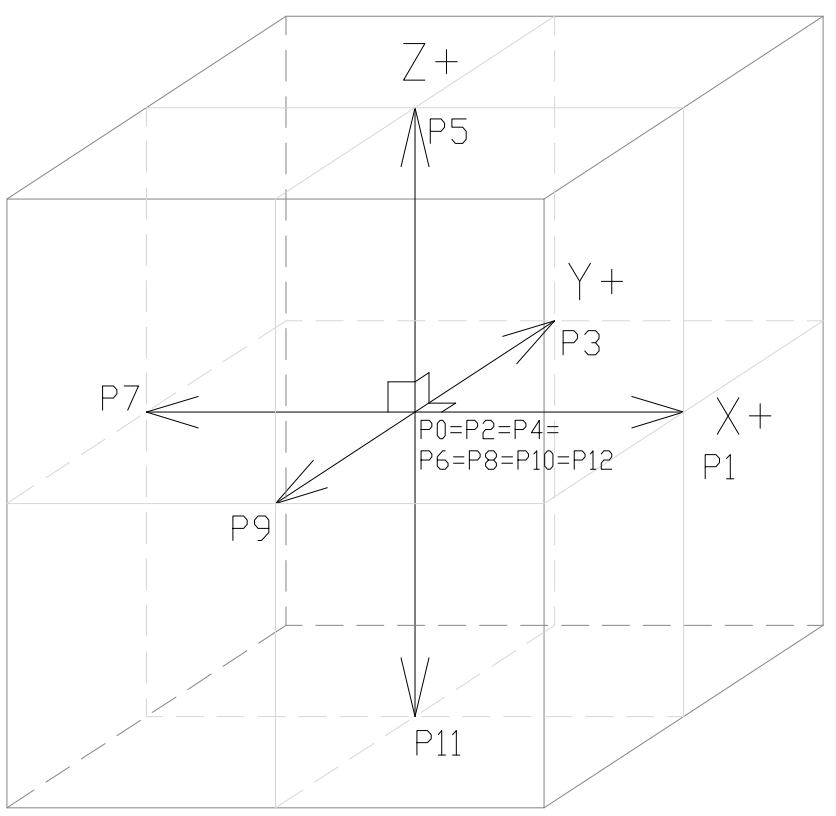

Figura 9: Pontos medidos para cada volume de medição avaliado.

O segundo procedimento realizado consistiu no seguinte:

- O robô é comandado para realizar rotações angulares. Teoricamente, a rotação não resulta em translação do sistema de coordenadas do flange. É realizada rotação
Tabela 2: Projeto de Experimento Angular.

\begin{tabular}{|c|c|c|c|}
\hline \multicolumn{4}{|c|}{ Pontos Medidos } \\
\hline \multirow{2}{*}{$\begin{array}{l}\text { Deslocamento } \\
\text { Angular do Robô }\end{array}$} & \multirow{2}{*}{ Sistema de Medição } & \multicolumn{2}{|c|}{ Velocidade do Robô } \\
\hline & & $10 \%$ & $100 \%$ \\
\hline \multirow{2}{*}{$20^{\circ}$} & K-SERIES & $(\mathrm{P} 0, \mathrm{P1}, \mathrm{P} 2, \ldots, \mathrm{P} 12)$ & $(\mathrm{P} 0, \mathrm{P} 1, \mathrm{P} 2, \ldots, \mathrm{P} 12)$ \\
\hline & iGPS & $(\mathrm{P} 0, \mathrm{P} 1, \mathrm{P} 2, \ldots, \mathrm{P} 12)$ & $(\mathrm{P} 0, \mathrm{Pl} 1, \mathrm{P} 2, \ldots, \mathrm{P} 12)$ \\
\hline \multirow{2}{*}{$\mathbf{1}^{o}$} & K-SERIES & $(\mathrm{P} 0, \mathrm{P} 1, \mathrm{P} 2, \ldots, \mathrm{P} 12)$ & $(\mathrm{P} 0, \mathrm{P} 1, \mathrm{P} 2, \ldots, \mathrm{P} 12)$ \\
\hline & iGPS & $(\mathrm{P} 0, \mathrm{P} 1, \mathrm{P} 2, \ldots, \mathrm{P} 12)$ & $(\mathrm{P} 0, \mathrm{P} 1, \mathrm{P} 2, \ldots, \mathrm{P} 12)$ \\
\hline \multirow{2}{*}{$0,5^{\circ}$} & K-SERIES & $(\mathrm{P} 0, \mathrm{P} 1, \mathrm{P} 2, \ldots, \mathrm{P} 12)$ & $(\mathrm{P} 0, \mathrm{P} 1, \mathrm{P} 2, \ldots, \mathrm{P} 12)$ \\
\hline & iGPS & $(\mathrm{P} 0, \mathrm{P} 1, \mathrm{P} 2, \ldots, \mathrm{P} 12)$ & $(\mathrm{P} 0, \mathrm{P} 1, \mathrm{P} 2, \ldots, \mathrm{P} 12)$ \\
\hline \multirow{2}{*}{$\mathbf{0 , 1 ^ { o }}$} & K-SERIES & $(\mathrm{P} 0, \mathrm{P} 1, \mathrm{P} 2, \ldots, \mathrm{P} 12)$ & $(\mathrm{P} 0, \mathrm{P} 1, \mathrm{P} 2, \ldots, \mathrm{P} 12)$ \\
\hline & iGPS & $(\mathrm{P} 0, \mathrm{P} 1, \mathrm{P} 2, \ldots, \mathrm{P} 12)$ & $(\mathrm{P} 0, \mathrm{P} 1, \mathrm{P} 2, \ldots, \mathrm{P} 12)$ \\
\hline \multicolumn{4}{|c|}{$\begin{array}{l}\mathrm{P} 0, \mathrm{P} 2, \mathrm{P} 4, \mathrm{P} 6, \mathrm{P} 8, \mathrm{P} 10 \text { e P12 } \\
\text { Sentido de medição angular em relação a } \mathrm{P} 0: \\
(-): \operatorname{P} 1\left(\theta_{A}\right), \operatorname{P} 9\left(\varphi_{B}\right) \text { e } \mathrm{P} 11\left(\phi_{C}\right) . \\
(+): \operatorname{P} 7\left(\theta_{A}\right), \mathrm{P} 3\left(\varphi_{B}\right) \text { e } \mathrm{P} 5\left(\phi_{C}\right) .\end{array}$} \\
\hline
\end{tabular}

de $20^{\circ}$ em torno do eixo X (giro A), seguida de rotação de $20^{\circ}$ (retorno à orientação original). É realizada a mesma operação para os eixos $\mathrm{Y}$ (giro B) e $\mathrm{Z}$ (giro C). Após a medição dos 7 pontos, o robô repete os movimentos, ainda com os mesmos $20^{\circ}$, porém no sentido inverso. A Figura 10 representa os giros em relação ao ponto de origem. Após a aquisição dos 13 pontos, o conjunto de movimentos é realizado para $1^{\circ}$, $0,5^{\circ}$ e $0,1^{\circ}$. O experimento está detalhado na Tabela 2.

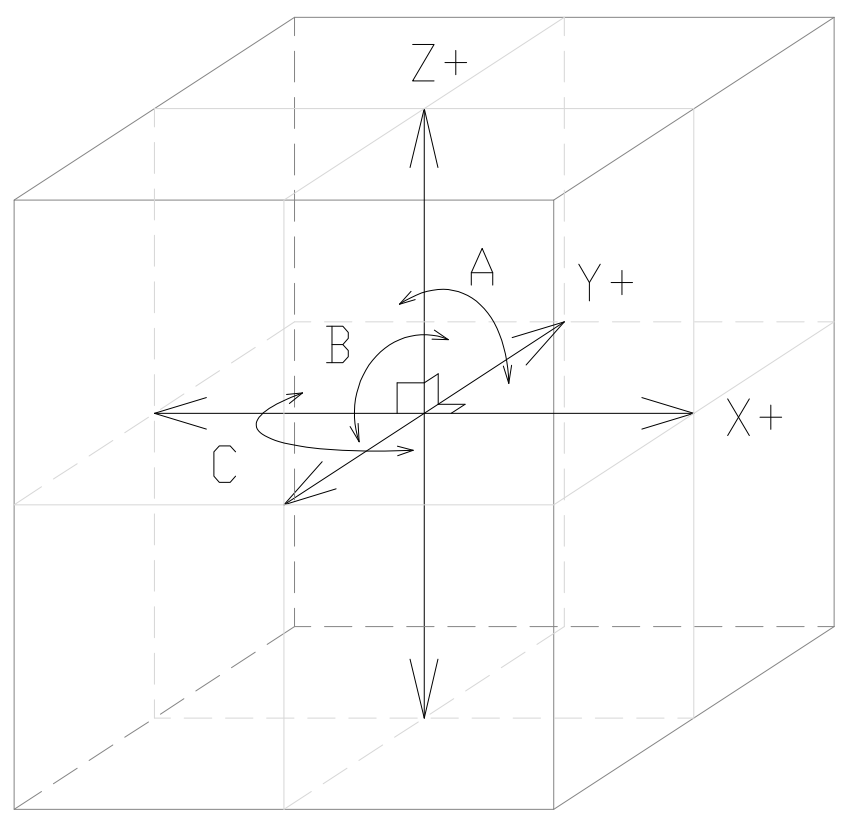

Figura 10: Movimentação angular avaliada.

- Após a realização dos procedimentos I e II sem carga, foi adicionada uma carga ao punho do robô correspondente ao seu payload (aproximadamente 90 $\mathrm{kg}$ ). Os procedimentos I e II foram, então, repetidos. 
Foram realizados 64 experimentos perfazendo um total de 1040 pontos medidos, sendo 624 com o K-SERIES e 416 com o iGPS, para os dois procedimentos propostos. A diferença no número de pontos entre os dois equipamentos é decorrente de problemas na configuração do sistema de coordenadas de referência do iGPS, que levou à necessidade de repetição dos experimentos e aquisição de maior número de pontos do que aquele realizado com o K-SERIES.

Deve-se ressaltar que, para cada ponto, foram obtidas as coordenadas lineares e angulares, considerando seis graus de liberdade (x, y, z, $\theta_{A}, \varphi_{B}$ e $\phi_{C}$ ) para ambos os sistemas metrológicos.

\subsection{Método de Análise dos Resultados}

A análise dos resultados baseou-se no cálculo de dois índices referentes respectivamente ao erro de posicionamento e ao erro de orientação do robô.

O erro de posicionamento é o módulo do vetor resultante da diferença entre as medidas do ponto realizadas com os sistemas metrológicos e a coordenada nominal/programada do robô em relação ao ponto $\mathrm{P} 0$.

O erro de posicionamento $(\Delta R)$ é modelado pela Equação (1), em que os índices $M E D$ e $N O M$ correspondem às coordenadas medida e nominal, respectivamente.

$$
\Delta R=\sqrt{\begin{array}{l}
\left(x_{M E D}-x_{N O M}\right)^{2}+\cdots \\
+\left(y_{M E D}-y_{N O M}\right)^{2}+\cdots \\
+\left(z_{M E D}-z_{N O M}\right)^{2}
\end{array}}
$$

De forma semelhante, o erro de orientação $(\Delta A)$ é calculado pela Equação (2).

$$
\Delta A=\sqrt{\begin{array}{l}
\left(\theta_{A M E D}-\theta_{A N O M}\right)^{2}+\cdots \\
+\left(\phi_{B M E D}-\phi_{B N O M}\right)^{2}+\cdots \\
+\left(\varphi_{C M E D}-\varphi_{C N O M}\right)^{2}
\end{array}}
$$

Todas as inferências estatísticas foram realizadas pelo método de análise de variâncias descrito em Montgomery (2006), considerando-se um nível de confiança de $95 \%$ ( $2 \sigma$ ou $\alpha=0,05)$, e com o auxílio do aplicativo de software "R" (R Development Core Team, 2009).

Foi considerado o modelo estatístico apresentado na Equação (3).

$$
\begin{aligned}
w_{i j k m} & =\mu+\tau_{i}+\beta_{j}+\delta_{k}+\alpha_{m}+\kappa_{n} \cdots \\
& +(\tau \beta)_{i j}+(\tau \delta)_{i k}+(\tau \alpha)_{i m}+\cdots \\
& +(\tau \beta \delta \alpha \kappa)_{i j k m n}+\varepsilon_{i j k m n}
\end{aligned}
$$

Tabela 3: Testes de hipóteses.

\begin{tabular}{cc}
\hline Hipótese nula: & Hipótese alternativa: \\
\hline$H_{0}: \tau_{1}=\tau_{2}=\cdots \tau_{i}=0$ & $H_{1}: \tau_{i} \neq 0$ \\
$\beta_{1}=\beta_{2}=\cdots \beta_{j}=0$ & $\beta_{j} \neq 0$ \\
$\delta_{1}=\delta_{2}=\cdots \delta_{k}=0$ & $\delta_{k} \neq 0$ \\
$\alpha_{1}=\alpha_{2}=\cdots \alpha_{m}=0$ & $\alpha_{m} \neq 0$ \\
$\kappa_{1}=\kappa_{2}=\cdots \kappa_{n}=0$ & $\kappa_{n} \neq 0$ \\
\hline
\end{tabular}

Tabela 4: Estatística descritiva de $\Delta R$.

\begin{tabular}{|l|l|l|}
\hline \multicolumn{3}{|c|}{$\Delta R[m m]$} \\
\hline Média & K-SERIES & iGPS \\
Erro padrão & 0,257 & 0,891 \\
Desvio-padrão & 0,011 & 0,083 \\
Mínimo & 0,264 & 1,683 \\
Máximo & $-0,559$ & $-1,051$ \\
Número de medidas (n) & 1,733 & 12,732 \\
Nível de confiança (95.0\%) & 624 & 416 \\
\hline
\end{tabular}

em que:

$$
\begin{aligned}
w_{i j k m}= & \text { Variável } \Delta R \text { ou } \Delta A \\
\mu= & \text { Média geral de } \Delta R \text { ou } \Delta A \\
\tau= & \text { Efeito do i-ésimo nível do fator Carga (Fator A) } \\
\beta= & \text { Efeito do j-ésimo nível do fator Velocidade (Fator } \\
& \text { B) } \\
\delta= & \text { Efeito do k-ésimo nível do fator } \\
& \text { Procedimento(Fator C) } \\
\alpha= & \text { Efeito do m-ésimo nível do fator Volume(Fator D) } \\
\kappa= & \text { Efeito do n-ésimo nível do fator Sistema(Fator E) } \\
\varepsilon= & \text { Erro aleatǿrio experimental }
\end{aligned}
$$

Os testes de hipóteses a serem verificados no modelo estão apresentados na Tabela 3 e verificam se existe influência dos diversos fatores nas variáveis medidas. Deve-se ressaltar que as mesmas hipóteses são válidas para as interações entre os fatores.

\subsection{Análise dos Resultados}

Todas as medidas realizadas com os sistemas metrológicos estão estatisticamente descritas na Tabela 4 e na Tabela 5 para $\Delta \mathrm{R}$ e $\Delta \mathrm{A}$, respectivamente. Deve-se ressaltar que os procedimentos I e II sem carga no robô foram repetidos uma vez com o sistema de medição K-SERIES, acarretando 208 medidas extras nos experimentos realizados. 
Tabela 5: Estatística descritiva de $\Delta A$.

\begin{tabular}{|l|l|l|}
\hline \multicolumn{3}{|c|}{$\Delta A\left[^{\circ}\right]$} \\
\hline Média & K-SERIES & iGPS \\
Erro padrão & 0,0176 & 0,2754 \\
Desvio padrão & 0,0007 & 0,0201 \\
Mínimo & 0,0187 & 0,4107 \\
Máximo & $-0,0792$ & $-0,3304$ \\
Número de medidas (n) & 0,0739 & 2,6485 \\
Nível de confiança (95,0\%) & 624 & 416 \\
\hline
\end{tabular}

Pela análise dos resultados, conclui-se que o sistema mais adequado é o K-SERIES. Este resultado era esperado, dado que a exatidão do K-SERIES é da ordem de dez vezes melhor que a do iGPS.

A análise da variância utilizando o modelo da Equação (3) foi realizada com o auxílio do software "R", um open source software, freeware, de uso acadêmico. Os resultados consideram todos os fatores e interações e estão apresentados na Figura 11 para $\Delta \mathrm{R}$ e na Figura 12 para $\Delta \mathrm{A}$. As figuras apresentam a forma de saída do software " $R$ " na análise de variância, incluindo os níveis de significância dos fatores A até $\mathrm{E}$ e das interações entre fatores. Os dados incluem os graus de liberdade (Df), a soma dos quadrados (Sum Sq), a média de quadrados (Mean Sq), o valor observado da estatística de teste ( $\mathrm{F}$ value) e o valor de prova $(\operatorname{Pr}(>F))$. Um valor de $\operatorname{Pr}$ maior do que 0,05 (correspondente ao nível de confiança de $95 \%$ adotado no experimento) indica que o fator influencia no parâmetro analisado. O número de asteriscos indica o nível de significância do fator ou da interação entre fatores. Em ambas as figuras, apresentam-se os fatores considerados e somente as interações significativas no intervalo de confiança adotado (95\%).

Pode-se observar da Figura 11 que os fatores que influenciam nos resultados referentes ao erro de posicionamento do robô são: o procedimento adotado (fator $\mathrm{C}$ : comandos de translação ou rotação), o volume de medição (fator D: comandos de translação de 0,1 a $500 \mathrm{~mm}$ e de rotação de $0,1^{\circ}$ a $20^{\circ}$ ) e o sistema de medição (fator E: K-SERIES ou iGPS). A influência do fator sistema não significa que o sistema de medição altera a resposta do robô, mas indica que um sistema é mais adequado que o outro para medição do erro.

Conclusões semelhantes são obtidas analisando-se as informações da Figura 12. Ambas as figuras apresentam interações de primeira ordem e interações de segunda ordem. $\mathrm{Na}$ análise dos erros de orientação, foram identificado erros de terceira ordem, ou seja, há uma condição em que os fatores carga, velocidade, volume e sistema de medição podem ser otmizados de modo tal que a resposta do robô apresentará o menor erro de orientação (interação entre os

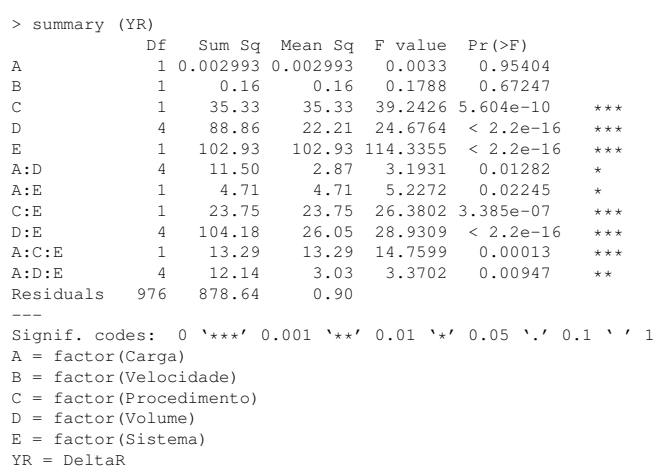

Figura 11: Figura . Análise de variância referente ao erro de posicionamento $\Delta R$.

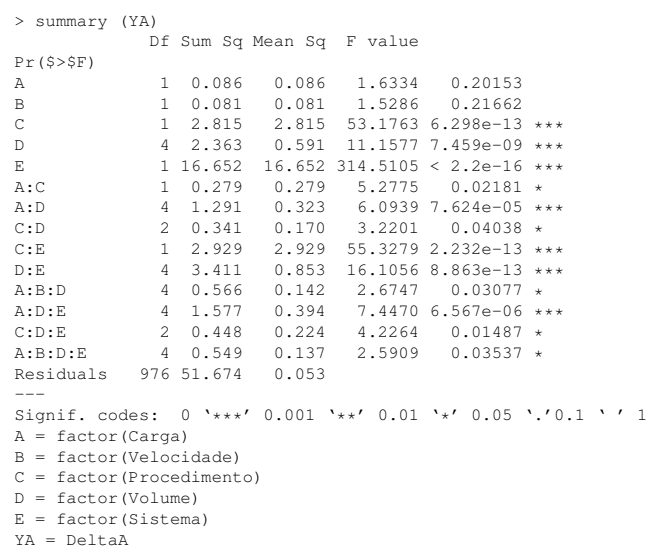

Figura 12: Análise de variância referente ao erro de orientação $\Delta \mathrm{A}$.

fatores A, B, D e E). Considerando-se o sistema de medição o K-SERIES como o melhor, basta combinar carga, velocidade e volume para obter-se uma resposta adequada do robô.

Outras conclusões relevantes podem ser obtidas da Figura 11 e da Figura 12. Tanto o fator carga quanto o fator velocidade (fatores A e B) eram esperados como fatores de influência significativa, mas verificou-se que têm pouca influência na resposta do robô, seja para erros de posicionamento, seja para erros de orientação, possivelmente devido ao robô ser um equipamento novo, onde as folgas nas juntas ainda atendam suas tolerâncias de projeto e manufatura. É importante citar que a simples adição da carga ao punho do robô ocasionou um deslocamento vertical de $4 \mathrm{~mm}$, não evidenciados neste trabalho. Este erro, porém foi corrigido pelo robô durante a execução do primeiro deslocamento após a adição da carga.

A Tabela 6 apresenta um resumo dos resultados obtidos 
Tabela 6: Resumo dos resultados.

\begin{tabular}{|c|c|c|c|c|c|c|}
\hline Sistema & Proc & Volume & $\begin{array}{l}\text { Média } \\
\Delta R\end{array}$ & $\begin{array}{l}\text { Desvio-padrão } \\
\Delta R\end{array}$ & $\begin{array}{l}\text { Média } \\
\Delta A\end{array}$ & $\begin{array}{l}\text { Desvio-padrão } \\
\Delta A\end{array}$ \\
\hline \multirow[t]{8}{*}{ K-SERIES } & \multirow[t]{4}{*}{ I } & 0,1 & 0,195 & 0,135 & 0,024 & 0,011 \\
\hline & & 05 & 0177 & 0212 & 0026 & 0.013 \\
\hline & & 1 & 0,138 & 0.237 & 0,023 & 0,011 \\
\hline & & 500 & 0,244 & 0,430 & 0,026 & 0,016 \\
\hline & \multirow[t]{4}{*}{ III } & 0,1 & 0,256 & 0,138 & 0,013 & 0,021 \\
\hline & & 0,5 & 0,349 & 0,132 & 0,012 & 0,020 \\
\hline & & 1 & $\begin{array}{l}0,329 \\
0,329\end{array}$ & 0,126 & 0 & $\begin{array}{l}0,021 \\
0,021\end{array}$ \\
\hline & & 20 & 0,372 & 0,391 & 0,008 & 0,021 \\
\hline \multirow[t]{8}{*}{ iGPS } & \multirow[t]{4}{*}{ I } & 0,1 & 0,263 & 0,089 & 0,419 & 0,212 \\
\hline & & 0,5 & 0,237 & 0,207 & 0,385 & 0,176 \\
\hline & & 1 & 0,164 & 0,297 & 0,217 & 0,172 \\
\hline & & 500 & $\begin{array}{l}0,104 \\
1,473\end{array}$ & 2,147 & $\begin{array}{l}0,559 \\
0,517\end{array}$ & $\begin{array}{l}0,633 \\
0,172\end{array}$ \\
\hline & \multirow[t]{4}{*}{ II } & 0,1 & 0,455 & 0,711 & 0,054 & 0,175 \\
\hline & & 0,5 & 0,825 & 0,770 & 0,082 & 0,162 \\
\hline & & 1 & 1.081 & 1.276 & 0,101 & 0,172 \\
\hline & & 20 & 2.625 & 3,248 & 0,387 & 0,727 \\
\hline
\end{tabular}

Tabela 7: Precisão e exatidão do robô.

\begin{tabular}{|l|l|l|l|l|}
\hline Procedimento & Deslocamento & Erro Médio & Precisão & Exatidão \\
& Nominal & $\Delta R[\mathrm{~mm}]$ & $\Delta R[\mathrm{~mm}]$ & $\Delta R[\mathrm{~mm}]$ \\
\hline Linear & $500 \mathrm{~mm}$ & 0,244 & 0,856 & 1,099 \\
& $1 \mathrm{~mm}$ & 0,138 & 0,472 & 0,610 \\
& $0,5 \mathrm{~mm}$ & 0,171 & 0,421 & 0,592 \\
& $0,1 \mathrm{~mm}$ & 0,195 & 0,269 & 0,464 \\
\hline \hline \multirow{4}{*}{ Angular } & Orientaç̃̃o & Erro Médio & Precisão & Exatidão \\
& Nominal & $\Delta A\left[^{\circ}\right]$ & $\Delta A\left[^{\circ}\right]$ & $\Delta A\left[{ }^{\circ}\right]$ \\
& $20^{\circ}$ & 0,008 & 0,041 & 0,049 \\
& $1^{\circ}$ & 0,010 & 0,043 & 0,052 \\
& $0,5^{\circ}$ & 0,012 & 0,041 & 0,053 \\
& $0,1^{\circ}$ & 0,013 & 0,041 & 0,054 \\
\hline
\end{tabular}

com as diversas configurações de experimento, considerando apenas os fatores significativos ( volume).

A verificação da adequabilidade do modelo estatístico adotado foi obtida pela análise qualitativa dos histogramas de $\Delta \mathrm{R}$ e $\Delta \mathrm{A}$, e do gráfico de normalidade dos resíduos. Concluiu-se que o modelo foi ajustado adequadamente, conforme observado na Figura 13. Os histogramas e os gráficos de normalidade dos resíduos indicam que as medições obedecem uma distribuição normal.

A análise de exatidão e precisão do robô pode ser resumida conforme apresentado na Tabela 7 e representado na Figura 14 e na Figura 15.

Neste trabalho, o termo precisão foi definido como sendo a repetitividade experimental do robô para um intervalo de confiança de $95 \%$, onde o fator de abrangência $(k=2,0$, aproximadamente) foi obtido por meio de uma distribuição " $t$-student" e multiplicado pelo desvio-padrão experimental. A exatidão do robô foi definida como sendo a soma do módulo do erro médio do robô com a precisão, também podendo ser definida como erro máximo para um nível de confiaça de $95 \%$.

Os resultados apresentados mostram que, dentro de uma faixa de medição de $\pm 500 \mathrm{~mm}$, o robô apresenta uma exatidão dentro de $\pm 0,5 \mathrm{~mm}$ até $\pm 1,1 \mathrm{~mm}$. Para medidas angulares, a exatidão ficou dentro de $\pm 0,05^{\circ}$ praticamente constante para toda da faixa de operação de $\pm 20^{\circ}$.

A comparação entre os sistemas K-SERIES e iGPS está

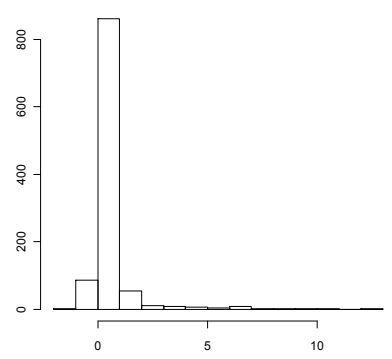

(a) Histograma de $\Delta R$

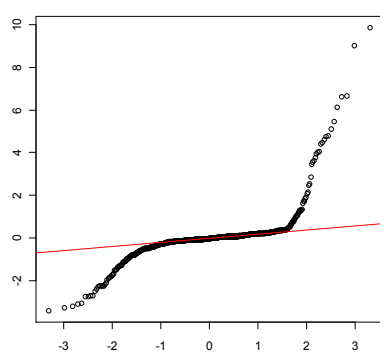

(c) Gráfico de normalidade dos (d) Gráfico de normalidade dos Resíduos de $\Delta R$

Figura 13: Verificação da aderência ao modelo estatístico.

ilustrada na Figura 16 e na Figura 17 para exatidão de posicionamento e de orientação, respectivamente.

Uma vez que o K-SERIES foi avaliado como o melhor sistema de medição, as conclusões apresentadas a seguir avaliam o robô e o sistema iGPS por meio da resposta do K-SERIES, considerando a aplicação de junção de segmentos fuselagem e conforme o processo descrito na Seção 4.

Considerando as limitações do sistema de visão acoplado ao efetuador do robô, a exatidão de posicionamento para distâncias da ordem de $500 \mathrm{~mm}$ indica que o robô é capaz de localizar a primeira referência presente na fuselagem

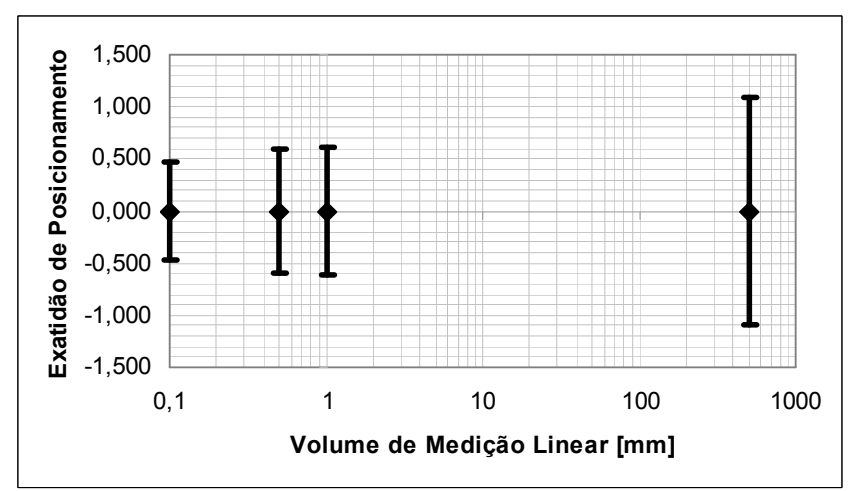

Figura 14: Curva de exatidão de posicionamento do robô. 


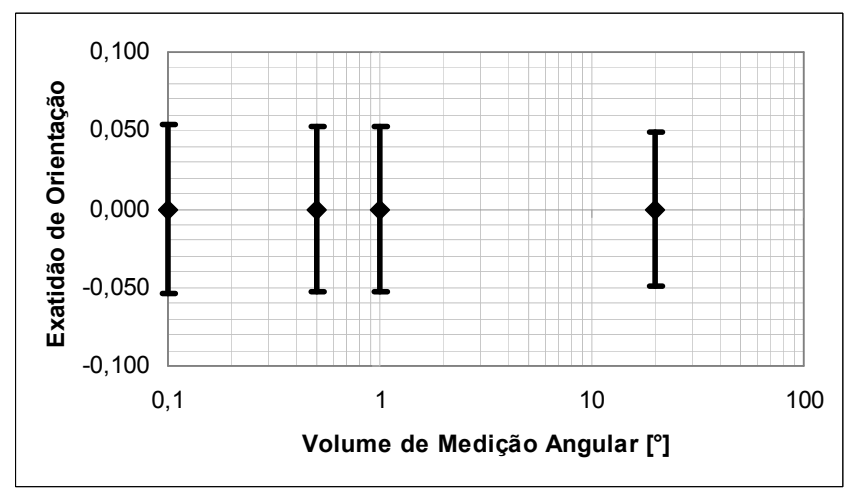

Figura 15: Curva de exatidão de orientação do robô.

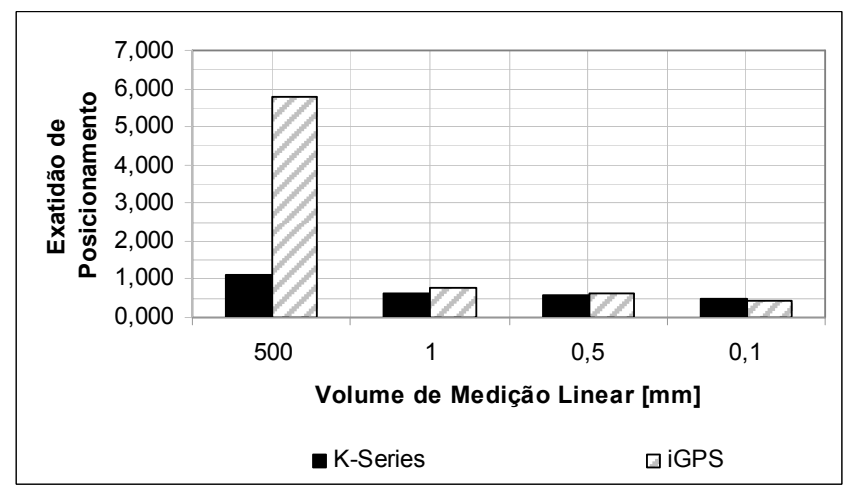

Figura 16: Comparação entre resultados do K-SERIES e do iGPS para exatidão de posicionamento.

partindo de qualquer posição no seu espaço de trabalho (Etapa 1 do processo).

A exatidão angular obtida com comandos de rotação permite afirmar que a utilização de um sistema de medição de perpendicularidade torna possível a obtenção da perpendicularidade exigida pelo processo por meio da correção da orientação do robô (Etapa 4 do processo). Outro resultado interessante referente à exatidão angular é que esta não é alterada significativamente pelo volume de trabalho.

Em contrapartida, a exatidão de posicionamento obtida com os comandos de translação limita o número de prendedores a serem inseridos entre duas referências em uma unidade, considerando a correção de posição por sistema de visão embarcado no efetuador robótico (Etapa 2 do processo). Este resultado direciona trabalho futuros para consideração de alternativas de processo que permitam melhorar a exatidão de posicionamento, tais como o uso de máscaras para identificar todos os pontos de furação.

Observa-se que os erros lineares para comandos angulares são em média maiores do que os obtidos com comandos

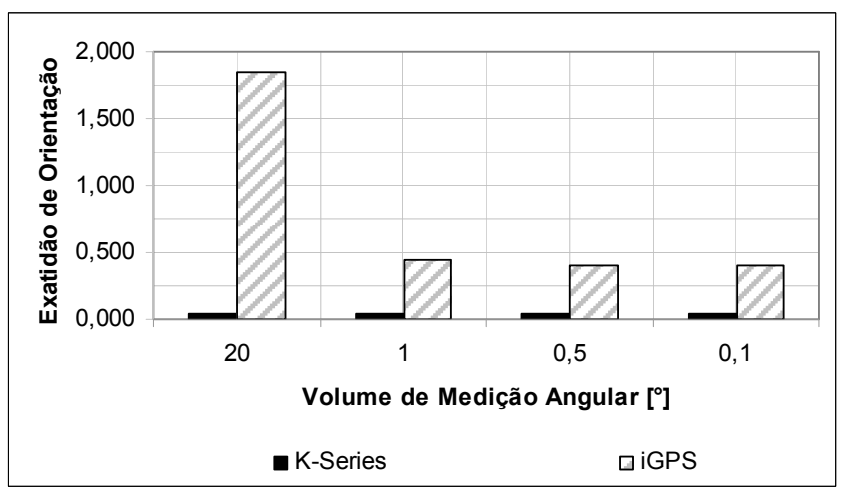

Figura 17: Comparação entre resultados do K-SERIES e do iGPS para exatidão de orientação.

lineares. O recíproco também é verdadeiro, ou seja, comando lineares resultam em maiores erros angulares do que os obtidos com comandos angulares. Este resultado indica que, para o processo de junção de fuselagens, deve-se analisar o impacto da correção de perpendicularidade (Etapa 4 do processo) na exatidão de posicionamento do robô.

Comparando os resultados do K-SERIES com os do iGPS, observa-se que a discrepância entre os dois sistemas varia significativamente com o volume de trabalho. No que se refere à exatidão de posição, o iGPS se confirmou equivalente ao K-SERIES para deslocamentos de até $1 \mathrm{~mm}$. No entanto, para um volume de trabalho de $500 \mathrm{~mm}$, o iGPS apresentou uma diferença de exatidão da ordem de $5 \mathrm{~mm}$. Além disso, existe uma discrepância significativa entre o iGPS e o K-SERIES na da exatidão da medição de orientação. Esta diferença é da ordem de $0,4^{\circ}$ para volumes menores que $1^{\circ}$ e da ordem de $1,8^{\circ}$ para volumes de $20^{\circ}$. Considerando a medição realizada pelo K-SERIES como referência, conclui-se que o iGPS não pode ser utilizado como alternativa para correção de orientação durante o processo de junção de fuselagens.

Estes resultados não são compatíveis com a exatidão especificada pelo fabricante para o sistema iGPS $(0,050 \mathrm{~mm}$ para um alcance de medição de $55 \mathrm{~m}$ ). Coloca-se, entre os próximos trabalhos, a análise da influência do procedimento de instalação dos sensores e configuração do sistema na exatidão do iGPS.

\section{CONCLUSÕES}

A montagem estrutural de fuselagens de aeronaves tem sido realizada de forma manual na indústria aeronáutica brasileira desde o início de suas atividades. Embora haja uma grande quantidade de prendedores e rebites nessas montagens, o que representa uma grande oportunidade de automação, 
não houve uma evolução significativa do processo até recentemente. Nas últimas décadas, fabricantes de aeronaves em outros países automatizaram vários processos com o emprego de grandes equipamentos. Estas máquinas normalmente são dedicadas a um produto, dificultando seu uso em modelos diferentes de aeronaves; por conseguinte, cada novo modelo demanda um equipamento diferente. Outra desvantagem desta abordagem para automação é o grande volume de investimento exigido, incompatível com a realidade brasileira.

Neste contexto, tornou-se primordial para a indústria aeronáutica brasileira o estudo de soluções alternativas e flexíveis para automação da montagem estrutural. Este trabalho apresenta os primeiros resultados de uma iniciativa nacional para projetar, desenvolver e testar um sistema flexível e de baixo custo de automação da montagem estrutural de aeronaves, adequado à realidade brasileira, baseada no uso de robôs industriais. Além da redução de custo, espera-se, como resultado da automação, uma redução significativa no tempo de processo de montagem estrutural.

É de consenso que robôs industriais, cujo principal mercado é a indústria automobilística, não atendem os requisitos das aplicações aeronáuticas, em particular, no que se refere a exatidão de posicionamento e orientação. Este artigo apresenta um estudo da adequabilidade dos robôs industriais para realização do processo de junção de segmentos orbitais de fuselagem. É apresentada uma solução de processo que contempla a correção de posição e orientação para realização das operações de furação e inserção de rebites. Com base nos requisitos desta solução, analisa-se, por meio de dois sistemas de medição de grandes volumes (iGPS e K-SERIES), a exatidão de posicionamento e de orientação do robô.

Os resultados apresentados permitem concluir que o robô em análise atende parcialmente a solução de processo adotada. A exatidão de orientação é suficiente para garantir a perpendicularidade necessária, mas a exatidão de posição limita o número de operações de furação e inserção de prendedores que podem ser executadas sem correção de posição.

Estes resultados são essenciais para direcionar os próximos trabalhos. Uma vez que modificações no processo têm impacto significativo no tempo de execução e no custo, a próxima atividade consiste na confirmação dos resultados obtidos utilizando, por exemplo, uma máquina de medição por coordenadas. Confirmados os resultados, soluções alternativas para o processo devem ser investigadas, tais como uso de máscaras para identificação na fuselagem de todos os pontos de furação.

Uma segunda conclusão importante deste trabalho se refere à comparação dos sistemas metrológicos utilizados. $\mathrm{O}$ iGPS apresentou resultados significativamente inferiores ao esperado. Como consequência, tem-se como próxima atividade a análise do impacto do procedimento de instalação dos sensores e configuração do sistema na exatidão do iGPS.

Esta avaliação dos sistemas metrológicos contribui também para a automação de outros processos. Um exemplo é o nivelamento e alinhamento de fuselagens. Neste caso, os sistemas convencionais, tais como máquinas de medição por coordenadas (MMC), não são apropriados devido ao tamanho do mensurando. Os sistemas metrológicos óticos analisados neste trabalho tornam-se uma solução viável para a automação destes processos devido às suas características metrológicas adequadas, flexibilidade de configuração e tempo de execução compatível com os tempos de processo.

\section{AGRADECIMENTOS}

Os autores agradecem o suporte financeiro das agências governamentais brasileiras: FINEP, CNPq e CAPES.

\section{REFERÊNCIAS}

Cibiel, C.; Prat, P. (2006). Automation for the Assembly of the Bottom Wing Panels on Strippers for the A320, SAE International, Document Number: 2006-01-3143.

Conrad, K.L.; Shiakolas, P.S.; Yih, T.C. (2000). Robotic Calibration Issues: Accuracy, Repeatability and Calibration. Proc. of the 8th Mediterranean Conference on Control \& Automation (MED), Patras (Greece).

Costa, S. (1996). Dassault Adaptive Cells. Industrial Robot, Vol. 23, No. 1, pp. 34-40.

DeVlieg, R.; Sitton, K.; Feikert, Ed.; Inmanet, J. (2002) ONCE (ONe-sided Cell End effector) Robotic Drilling System. SAE International, Document Number: 2002-01-2626.

Iovenitti, P.G.; Mutapcic, E.; Nagarajah, C.R. (2001) Positioning and Orienting a Drill Axis on a Curved Surface, Int. Journal of Advanced Manufacturing Technology, No. 17, pp.484-488.

Kihlman, H. (2005). Affordable Automation for Airframe Assembly-Development of Key Enabling Technologies, $\mathrm{PhD}$ thesis, Linköping University, Linköping (Sweden).

Kihlman, H.; Loser, R. (2003). 6DOF Metrology-integrated Robot Control. SAE International, Document Number: 2003-01-2961.

Kleebaur, R. (2005). Automation in Aircraft Assembly, Planet AeroSpace, n. 4. 
KUKA Roboter (2009). Specification KR 210-2. Disponível em: www.kuka-roboter.com.br . Acesso em: junho de 2009.

Freemann, P. (2006). A Novel Means of Software Compensation for Robots and Machine Tools Philip Freeman. SAE International, Document Number: 2006-01-3167.

Furtado, L.F.F.; Villani, E.; Sutério, R. (2009). A Perpendicularity Measurement System for Industrial Robots. Proc. of the 20th International Congress of Mechanical Engineering (COBEM), Gramado.

Summers, M. (2005). Robot Capability Test and Development of Industrial Robot Positioning System for the Aerospace Industry. SAE International, Document Number: 2005-01-3336.

Melo, R.; Furtado, L.F.F.; Sutério, R.; Trabasso, L.G. (2008). Análise de Viabilidade para Medição $e$ Montagem de Estruturas de Grandes Volumes com o Sistema GPS-Indoor, Relatório Técnico, Instituto Tecnológico de Aeronáutica, São José dos Campos.

Metris (2005). K610-CMM the High-Accuracy Portable CMM. Disponível em $<$ www.metris.com $>$. Acesso em: junho de 2009.

Metris (2008). Data Sheet iGPS Brochure. Disponível em $<$ www.metris.com >. Acesso em: outubro de 2009.

Montgomery, D.C. (2004). Design and Analysis of Experiments. 6th edition, John Wiley \& Sons.

Munroe, J.; Wilkins, K.; Gruber, M. (2000) Integral Airframe Structures (IAS) - Validated Feasibility Study of Integrally Stiffened Metallic Fuselage Panels for Reducing Manufacturing Costs. Technical Report, NASA/CR-2000-209337, NASA.

R Development Core Team (2009). $R$ : A language and environment for statistical computing. R Foundation for Statistical Computing, Vienna, Austria.

Saadat, M.; CRETIN, L. (2002). Measurement systems for Large Aerospace Components, Birmingham.

Seong-Ho, K.; Delbert, T. (2004). Indoor Gps Metrology System with 3d Probe for Precision Applications, PhD thesis, University of Texas, Austin Texas (USA).

Webb, P.; Eastwood, S.; Jayweera, N.; Ye, C.; Keown, C.M. (2006). An Automated Fuselage Panel Assembly and Riveting Cell - Validation and Testing. SAE International, Document Number: 2006-01-3142.
Webb, P.; Jayaweera, N. (2007). Adaptive robotic assembly of compliant aero-structure components. Robotics and Computer-Integrated Manufacturing, Vol. 23, No. 2, pp. 180-194. 